Петрова Зоя Кирилловна (Москва). Доктор архитектуры, советник РААСН. Главный научный сотрудник отдела «Территориальные основы градостроительства» ФГБУ «ЦНИИП Минстроя России» (119331, Москва, просп. Вернадского, 29. ЦНИИП Минстроя России). Эл.почта: petrovaz777@mail.ru.

Petrova Zoya K. (Moscow). Doctor of Architecture, Advisor of RAACS. Chief Researcher at the Department of Territorial Foundations of Urban Development at the the Institute for Research and Design of the Ministry of Construction and Housing and Communal Services of Russia (29 Vernadskogo avenue, Moscow, 119331. TsNIIP). E-mail: petrovaz777@mail.ru.

(- Петрова 3.К., 2021. Academia. Архитектура и строительство, № 4, стр. 86-93.

\title{
Модернизация сельских поселений путем применения инновационных технологий
}

\author{
3.К.Петрова, ЦнИИП Минстроя России, Москва
}

Статья посвящена исследованию проблемы возрождения сельских поселений путём модернизации инженерной инфраструктуры. Научные исследования автора направлены на улучшение качества среды жизнедеятельности сельского населения. В предыдущей статье ${ }^{*}$ исследование было ограничено проблематикой архитектурно-планировочной организации застройки в сельскохозяйственных поселениях с жильём для постоянного проживания людей в условиях климата умеренного пояса Центрального федерального округа России. В настоящей статье освещаются результаты исследования сельских населённых пунктов, связанные с модернизацией их планировочной структуры за счёт применения инновационных инженерных систем и оборудования. На основании изучения опыта применения инновационных инженерных систем в сельскохозяйственных поселениях в отечественной и зарубежной практике были разработаны рекомендации и предложения по применению современных инновационных инженерных систем энергоснабжения, водоснабжения, водоотведения/канализации для создания комфортной среды жизнедеятельности в сельской местности. Ближайшее будущее в сфере энергоснабжения сельских поселений состоит в применении энергетических систем, использующих газ, наряду с развитием систем, работающих на возобновляемых источниках энергии. Рекомендуется строительство и реконструкция жилых домов на основе экологического стандарта дома: «энергопассивный дом» и «энергоэффективный дом» для снижения энергозатрат на эксплуатацию зданий.

Ключевые слова: сельские поселения, модернизация, инновационные инженерные системы энергоснабжения, водоснабжения, водоотведения / канализации.

*) Петрова 3.К. Модернизация планировочной организации сельских поселений // Academia. Архитектура и строительство. - 2021. - № 2. - С. 103-110.

\section{Modernization of Rural Settlements through the Use of Innovative Technologies}

Z.K.Petrova, TsNIIP Minstroy Russia, Moscow

The article is devoted to the study of the problem of the revival of rural settlements through the modernization of engineering infrastructure. The author's research is aimed at improving the quality of the living environment of the rural population. In the previous article, the study was limited to the problems of architectural and planning organization of development in agricultural settlements with housing for permanent residence of people in the climate of the temperate zone of the Central Federal District of Russia. This article presents the results of a study of rural settlements related to the modernization of their planning structure through the use of innovative engineering systems and equipment. Based on the study of the experience of using innovative engineering systems in the domestic and foreign practice of agricultural settlements, recommendations and proposals were developed for the use of modern innovative engineering systems of energy supply, water supply, sanitation/sewerage to create a comfortable living environment in rural areas. The near future in the field of energy supply to rural settlements is the use of energy systems that use gas, along with the development of systems that run on renewable energy sources. We recommend the construction and reconstruction of residential buildings based on the environmental standard of the house: "energy-safe house" and "energy-efficient house" to reduce energy costs for the operation of buildings. In large, big, and medium-sized rural settlements, it is possible to use centralized water supply systems. In small settlements, it is advisable to use local and autonomous water supply systems using artesian wells. It is proposed to create innovative treatment facilities for domestic and industrial wastewater, including sewage pumping stations, sewer networks. In rural residential and public buildings located in small towns and villages, it is recommended to use a modern, self-contained wastewater treatment system. 
Keywords: rural settlements, modernization, innovative engineering systems of power supply, water supply, drainage/ sewerage.

Сегодня на пути повышения выживаемости человечества и достижения индивидуальной экологической безопасности (устойчивости), по мнению исследователя экологических проблем цивилизации Д. Медоуза, большое значение приобретают следующие четыре принципа [1]:

1) необходимость дублирования некоторых функций. Например, наличие нескольких источников электрической и тепловой энергии в индивидуальном доме - централизованного электроснабжения от сети, дровяной печи, газового электрогенератора, солнечных батарей и/или солнечных коллекторов;

2) необходимо уметь изменять привычный образ жизни и линию поведения - например, ограничить себя в расточительных расходах энергии, воды и других ресурсов;

3) наличие в жилье запасов продуктов, воды, топлива и т.п.;

4) организация сообщества граждан в жилой застройке для взаимопомощи в процессе выживания в случае природных и техногенных катастроф.

Процесс создания комфортной среды жизнедеятельности в сельской местности на современном этапе во многом связан с наличием инновационных инженерных систем, которые позволяли бы обеспечить электрической и тепловой энергией, водоснабжением и канализацией жилые, общественные и производственные здания. Сегодня большая доля жилищного фонда в сельской местности не имеет полного инженерного обеспечения водопроводом, канализацией, горячим водоснабжением, газом и так далее [2]. При этом лучше всего ситуация обстоит с обеспеченностью сетевым или сжиженным газом - удельный вес обеспечения им всего жилищного фонда составил на 1 января 2019 года - 68,6\%, в том числе в городах - 71,9\%, в сельской местности - 59,4 \% [3]. К 2035 году уровень газификации регионов должен составить 82,9\%. Так, в 2019 году 84\% общей площади жилищного фонда Российской Федерации было оборудовано водопроводом, в том числе сельского фонда - 63\%; 79\% всего жилищного фонда оборудовано водоотведением (канализацией), из них на сельский жилищный фонд приходится 52\%; 72\% всего жилищного фонда - горячим водоснабжением, в том числе сельского жилищного фонда - 40\%; напольными электроплитами по стране - 25\%, в том числе сельского фонда - 8\% [4].

В ряде субъектов Российской Федерации, входящих в состав Северо-Западного федерального округа, низкая плотность населения, низкая инфраструктурная оснащённость и высокая стоимость доставки энергоносителей обусловливают целесообразность использования возобновляемых источников энергии и местных видов топлива. В Центральном федеральном округе в целях устранения энергетических барьеров социально-экономического развития и использования потенциала энергосбережения прогнозировалось снизить энергоёмкость регионального внутреннего продукта (без учёта Москвы).

К сожалению, действующая нормативная база в области энергоэффективности в нашей стране не оказывает существенного влияния на энергосбережение.

В настоящее время действует Федеральный закон от 23.11.2009 № 261-Ф3 «0б энергосбережении и о повышении энергетической эффективности и о внесении изменений в отдельные законодательные акты Российской Федерации». Согласно этому закону жилые здания, подпадающие под категорию индивидуального строительства (количество этажей не должно превышать трёх), в своей проектной документации не должны содержать никаких сведений об энергоэффективности. Причём это не будет препятствием для получения разрешения на строительство или эксплуатацию помещений [5].

При этом в СП 55.13330.2016 «Дома жилые одноквартирные. Актуализированная редакция СНиП 31-02-2001» (с Изменением № 1) ${ }^{1}$ разработанном в соответствии с Федеральным законом от 30 декабря 2009 г. № 384-Ф3 «Технический регламент о безопасности зданий и сооружений» ${ }^{2}$, предусмотрено при проектировании одноквартирных или блокированных зданий (высотой до трёх этажей) выполнение требований вышеназванного закона с учётом СП 50.13330.2012 «Тепловая защита зданий. Актуализированная редакция СНиП 23-022003» (с Изменением № 1) ${ }^{3}$.

Так, согласно пункту 1.1 - СП 55.13330.2016 «...распространяется на проектирование, строительство, реконструкцию жилых одноквартирных домов (далее - дома) с количеством наземных этажей не более чем три, отдельно стоящих или блокированной застройки»; пункту 1.2 « ... распространяется на жилые одноквартирные дома со встроенными, пристроенными или встроенно-пристроенными нежилыми помещениями, общественного или производственного (ремесленного или сельскохозяйственного) назначения». В разделе 9 «Энергосбережение» данного Свода правил установлены требования к внутреннему микроклимату помещений и другим условиям проживания, обеспечивающим эффективное и экономное расходование невозобновляемых энергетических ресурсов при его эксплуатации. Таким образом, требования энергоэффективности распространяются и на индивидуальные сельские жилые дома.

Необходимо внесение изменения в законодательство в части проектирования и строительства жилых домов, подпадающих под категорию индивидуального строительства с

${ }^{1}$ СП 55.13330.2016 «Дома жилые одноквартирные. Актуализированная редакция СНиП 31-02-2001 (с Изменением N 1)». (http://docs.cntd.ru/ document/456039916).

2 Федеральный закон от 30 декабря 2009 г. № 384-Ф3 «Технический регламент о безопасности зданий и сооружений» (последняя редакция) (http://www.consultant.ru/document/cons_doc_LAW_95720/).

${ }^{3}$ СП 50.13330.2012 «Тепловая защита зданий. Актуализированная редакция СНиП 23-02-2003» (с Изменением № 1) (http://docs.cntd.ru/ document/1200095525). 
количеством этажей не более трёх. На эти дома должны распространяться положения Федерального закона «0б энергосбережении и о повышении энергетической эффективности, и о внесении изменений в отдельные законодательные акты Российской Федерации».

В сельских жилых домах основные проблемы их низкой энергоэффективности связаны с конструктивными решениями, отсутствием инновационных инженерных систем и оборудования, в том числе: плохо утеплённой «оболочкой» (стены, окна, двери и другие конструкции); большими потерями тепла в системе вентиляции; отсутствием устройств, регулирующих нагревание отопительных приборов в зависимости от температуры наружного воздуха; отсутствием систем, использующих альтернативные источники энергии.

Пассивный дом, или экодом (нем. Passivhaus, англ. passive house) - сооружение, основной особенностью которого является низкое энергопотребление за счёт применения пассивных методов энергосбережения. В идеале пассивный дом должен быть независимой энергосистемой, не требующей расходов на поддержание комфортной температуры. Отопление пассивного дома должно происходить благодаря теплу, выделяемому живущими в нём людьми и бытовыми приборами. Горячее водоснабжение также может осуществляться за счёт установок возобновляемой энергии: тепловых насосов или солнечных водонагревателей (коллекторов).

Современный сельский жилой дом прежде всего должен соответствовать стандарту экологического дома - «пассивный жилой дом». В таком доме потребление ресурсов максимально снижено за счёт оптимальной ориентации здания, компактности объёма и утепления его «оболочки» с герметизацией стыков конструкций, использования тройного остекления и энергосберегающих стёкол, оптимизации расхода электроэнергии. При этом недостающая энергия в системе отопления и горячего водоснабжения здания восполняется путём пассивных способов использования возобновляемых источников энергии, то есть устройства солнечного коллектора, теплового насоса и рекуператора тепла отработанного воздуха (рис. 1) [6].

В энергоэффективном доме наряду с повышением коэффициента полезного использования энергии во всех энергетических процессах, ликвидацией лишней траты энергии экономический эффект достигается, главным образом, за счёт активных способов использования возобновляемых источников энергии. То есть солнечная радиация, энергия ветра, гидро-, геотермальная энергия и тому подобное используются полностью или частично для отопления, горячего водоснабжения здания (рис. 2).

Существенное влияние на выбор эффективного источника энергоснабжения, системы водоснабжения и водоотведения/ канализации оказывают географические, климатические и

\footnotetext{
${ }^{4}$ Все изображения взяты из открытых источников сети Интернет.
}

градостроительные характеристики территории, местоположение объекта, а также численность населения и планировочная структура сельской малоэтажной застройки. Инновационным решением проблемы повышения энергоэффективности малоэтажной застройки должно стать применение наряду с централизованными системами децентрализованных (автономных и локальных) систем электроснабжения, в том числе использование альтернативных/возобновляемых источников энергии. Предлагается применять также децентрализованные (автономные и локальные) системы теплоснабжения зданий $[1 ; 7]$.

Зоны электро- и теплоснабжения застройки и зданий можно разделить на три группы:

1) зоны централизованного электроснабжения - снабжения от существующих электростанций, локального теплоснабжения (котельная) или электроснабжения (СЭС и ВЭС);

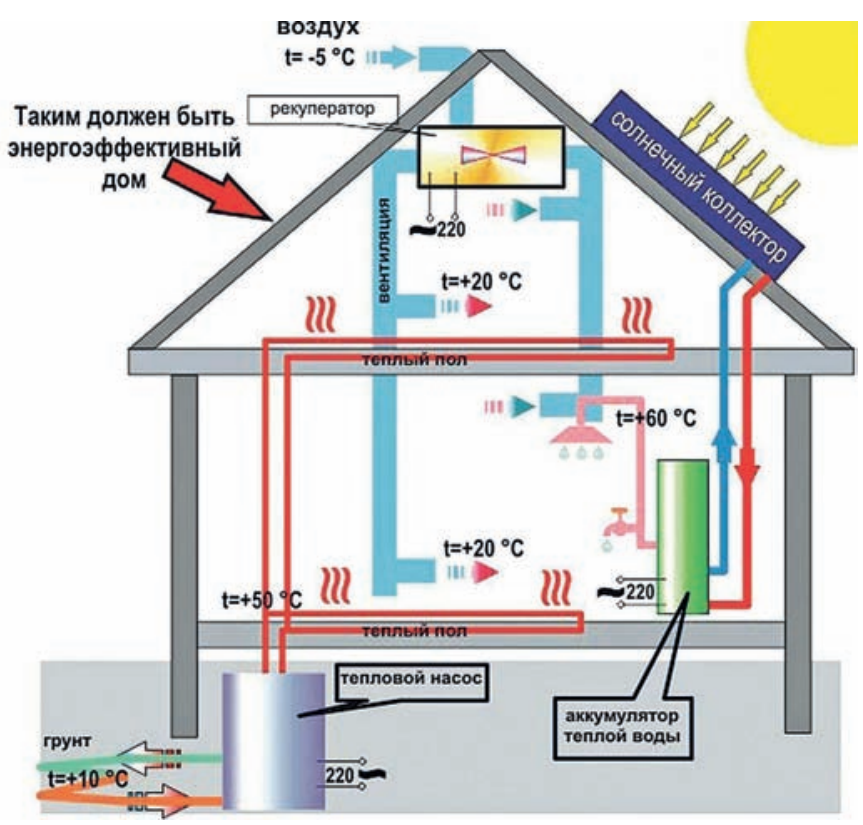

Рис. 1. Модель пассивного дома ${ }^{4}$

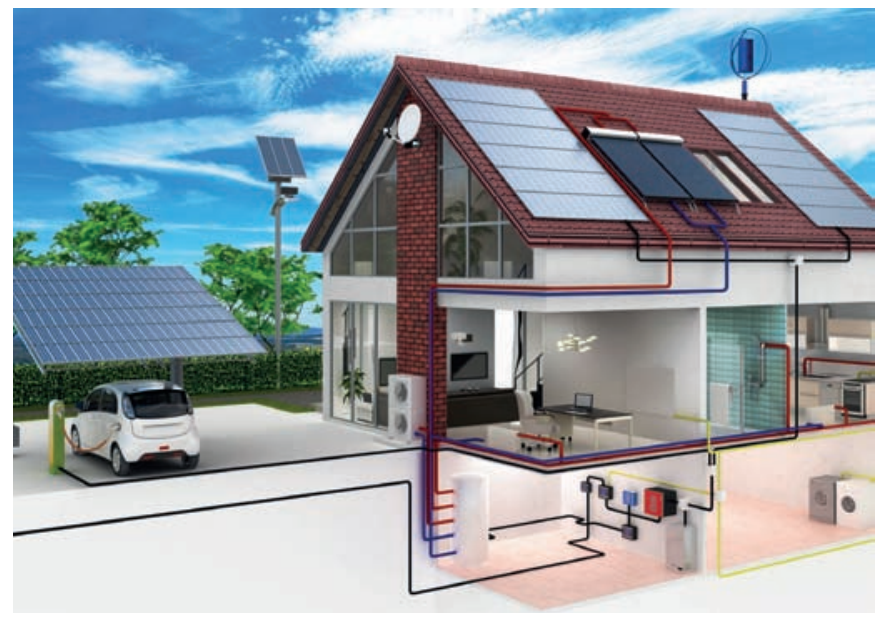

Pис. 2. Энергоэффективный дом с солнечными батареями и коллекторами 
2) зоны автономного тепло- и электроснабжения зданий;

3) зоны гибридного тепло- и электроснабжения (централизованного электроснабжения, локального или автономного тепло- и электроснабжения.

В совокупности эти системы создают комфорт и позволяют поддерживать качественные условия проживания. Если хотя

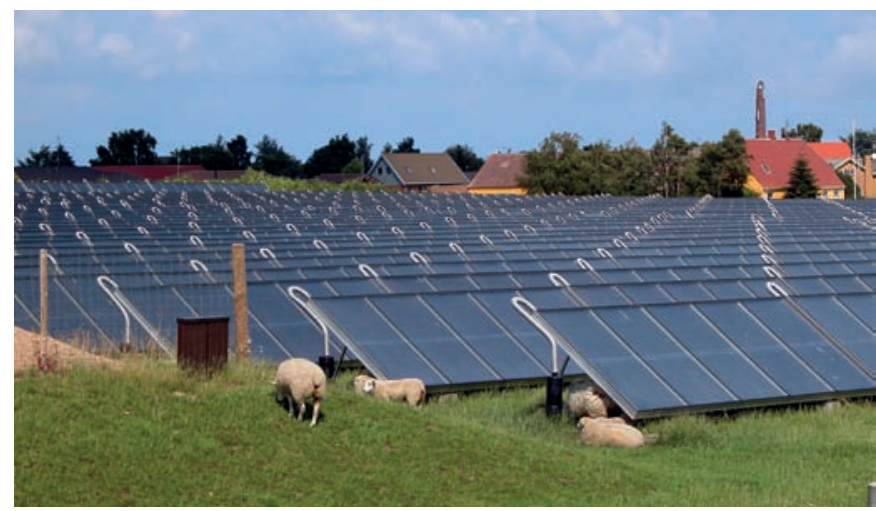

Рис. 3. Солнечная электростанция. Марстал, Дания. Солнечные батареи, имеют общую площадь 18365 кв. м. Мощность электростанции покрывает треть энергопотребления малого города

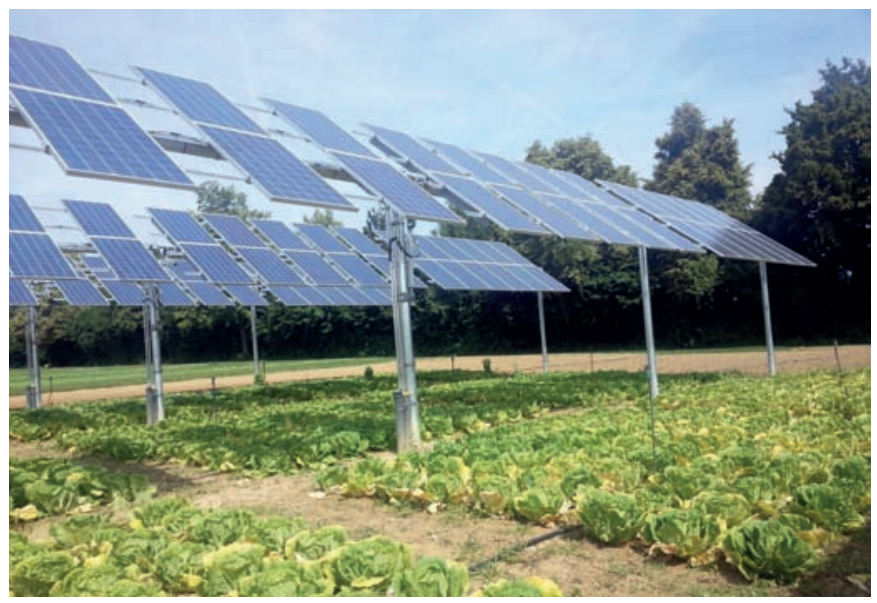

Рис. 4. Солнечные батареи как отдельные установки на территории сельского населённого пункта

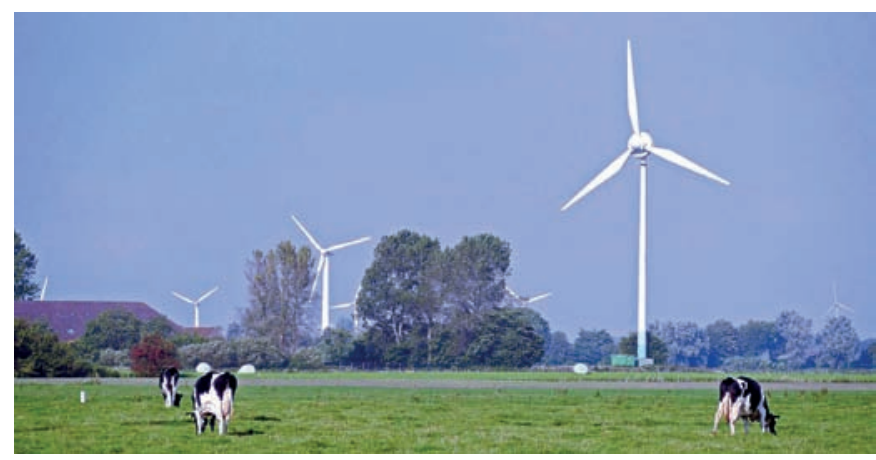

Puс. 5. Ветрогенераторы в прибрежном районе на лугу рядом с фермой. Восточная Фризия, Германия бы одна из систем перестаёт функционировать, нормальные условия жизни и труда нарушаются.

Например, периодическое отключение электроэнергии - это главная проблема в деревне [8]. Жизнедеятельность сельского населения существенно зависит от снабжения электроэнергией. Альтернативные источники электроэнергии в сельских поселениях способны обеспечить комфортное проживание сельских жителей в XXI веке.

Альтернативными источниками электроэнергии в сельских населённых пунктах, как правило, выступают виды топлива: сжатый и сжиженный газ, биогаз, генераторный газ, углеводородное топливо и другие. В мировой практике для обеспечения экологической безопасности применяют неисчерпаемые ресурсы, то есть возобновляемые источники энергии. Их использование сокращает или замещает потребление энергетических ресурсов более дорогих и дефицитных видов топлива.

В ближайшем будущем в сфере развития энергоснабжения сельских поселений наряду с альтернативными видами топлива будет использоваться ископаемое топливо. Для теплоснабжения крупных и больших сельских населённых пунктов, которые подключены к системе магистрального газоснабжения, предлагается применять котельные большой мощности - паровые и водогрейные блочно-модульные и стационарные. Такие котельные будут снабжать теплом прежде всего общественные здания: школу, детское дошкольное учреждение, административное здание, медучреждение, клуб, торговые объекты. В крупных сёлах возможно также локальное теплоснабжение жилых и производственных зданий. В малых и средних сельских населённых пунктах целесообразно применение, в основном, автономных или гибридных (автономных и локальных) систем теплоснабжения.

В сельских поселениях для получения электроэнергии при авариях в сетях централизованного электроснабжения предлагается использовать генераторы. На рынке имеются бензиновые, дизельные и газовые генераторы [9].

Применение солнечных батарей рекомендуется как централизованно, так и в частном секторе. Они предусматриваются в качестве как отдельных установок на земле, солнечных электростанций (СЭС), так и на крышах зданий в составе гибридных систем (рис. 3,4$)$. Десять солнечных модулей с мощностью каждого по 300 Вт могут обеспечивать электричеством частный дом круглый год на протяжении 25-ти лет. Вместе с тем цена такого оборудования составит 150-200 тыс. рублей, в то время как цена бензогенератора - 15-30 тыс. рублей. Но установка солнечных батарей окупается в течение десяти лет, дальше даёт прибыль. Следует отметить, что в последние годы отмечается тенденция снижения стоимости солнечных батарей.

Так, за рубежом имеются фермерские хозяйства, функционирующие автономно от центральной электрической сети благодаря ветровым установкам (рис. 5). Принцип действия ветровой установки заключается в преобразовании потока ветра в электроэнергию с помощью генератора. Цена такой 
бытовой установки мощностью 2-5 кВт составляет порядка 100-200 тыс. рублей, а промышленной установки - до одного миллиона рублей.

Сельский дом, к сожалению, не может обойтись без генератора как альтернативы централизованному электроснабжению. Он представляет собой замену центральной энергосети в моменты отключения. Следует только правильно выбрать параметры генератора - подбирать исходя из требуемой мощности. Чаще для частных жилых зданий используются генераторы от 5 до 15 кВт. Так, бензогенератор не относиться к альтернативному источнику электроэнергии, но является и наиболее доступным по цене.

Если сельский населённый пункт подключён к магистральной подаче природного газа и предусмотрено снабжение магистральным газом жилья, то оптимальным решением для отопления дома будет установка газового оборудования. Эксплуатация такой системы отопления несравнимо экономичнее всех остальных, так как стоимость газа относительно невысока, особенно в сравнении с электроэнергией. Отпадают всяческие проблемы по дополнительному приобретению, транспортировке и складированию топлива, характерные для твёрдо- или жидкотопливных установок. При соблюдении всех требований по установке и правил использования газовое оборудование для отопления дома вполне безопасно, обладает высокими эксплуатационными показателями. Главное - правильно определиться с нужной моделью газового котла, чтобы он в полной мере соответствовал конкретным условиям эксплуатации, отвечал пожеланиям владельцев по функциональности и удобству пользования.

Геотермальный тепловой насос представляет собой возобновляемый источник тепловой энергии земли, эффективную и экономичную систему отопления и охлаждения. Преимущества теплового насоса заключаются в дешёвой тепловой энергии, так как не используется сырье, растущее в цене; низком потреблении электрической мощности, бесплатном кондиционировании воздуха; не нужны специальные помещения, дымоходы и вентиляция; экологичен и пажаробезопасен.

Например, расходы на отопление тепловым насосом за год для дома площадью 200 кв. м аналогичны расходам на энергоснабжение природным газом. Но при этом нет расхода ископаемого топлива и выбросов парниковых газов. Особо следует отметить надёжность теплового насоса - он может работать до ста лет. Главный его недостаток - высокой стоимость (720 тыс. рублей). Вместе с тем эти расходы окупаются за десять лет [10].

Большинство малых населённых пунктов не имеют системы централизованного водоснабжения зданий. Водоснабжение осуществляется из колодцев или колонок. Ресурс системы централизованного водоснабжения в больших сельских поселениях, как правило, исчерпан: трубы нарушены коррозией, скважины заилились. Подача достаточного количества воды в населённый пункт позволяет поднять общий уровень его благоустройства. Бесперебойное обеспечение качественной водой людей, животных и технологических процессов - необ- ходимое условие развития сельского хозяйства. Большинство сельских населённых пунктов нуждается в модернизации системы водоснабжения.

Водопровод, идущий из колодца прямо в дом, является одной из самых надёжных, простых и доступных автономных систем в сельском доме. Основное отличие колодцев от скважин состоит в регулярном бесперебойном заборе воды. В основном это касается малозаглублённых песочных скважин, которые могут заиливаться [11].

Самый надежный источник для водоснабжения частного дома при постоянном в нём проживании - артезианская скважина (рис. 6). Есть два основных способа организовать водоснабжение частного дома из скважины - схема может предусматривать использование артезианской скважины (глубиной до 150 м) или так называемой «на песок» (глубиной 15-50 м). Различаются они не только по глубине, но ещё и по сроку службы. Первые могут использоваться до пятидесяти лет, а срок службы вторых обычно от восьми до двадцати лет [12]. Минусами скважины является более дорогое, по сравнению с рытьём колодца, бурение а также необходимость применения более дорогих скважинных насосов.

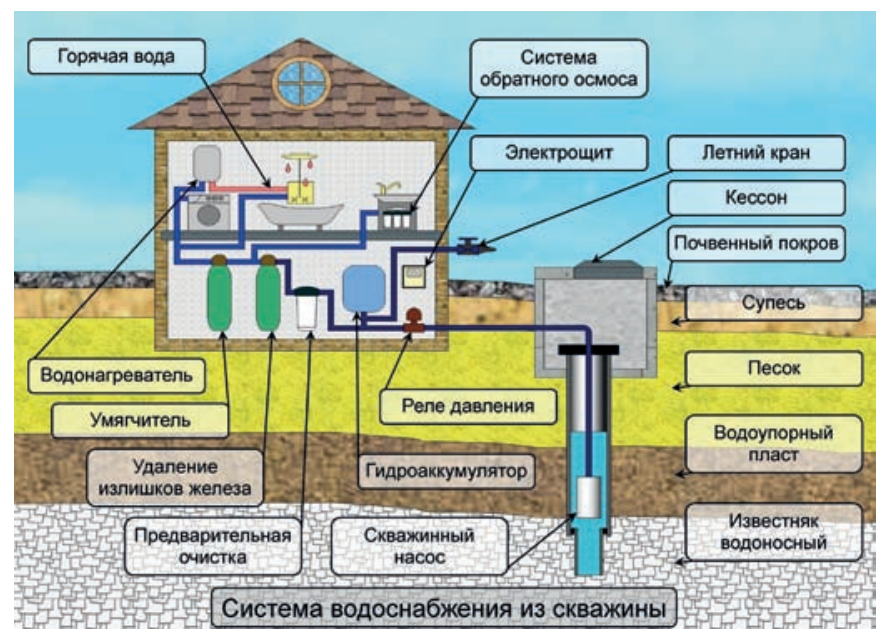

Puс. 6. Артезианская скважина для водоснабжения дома

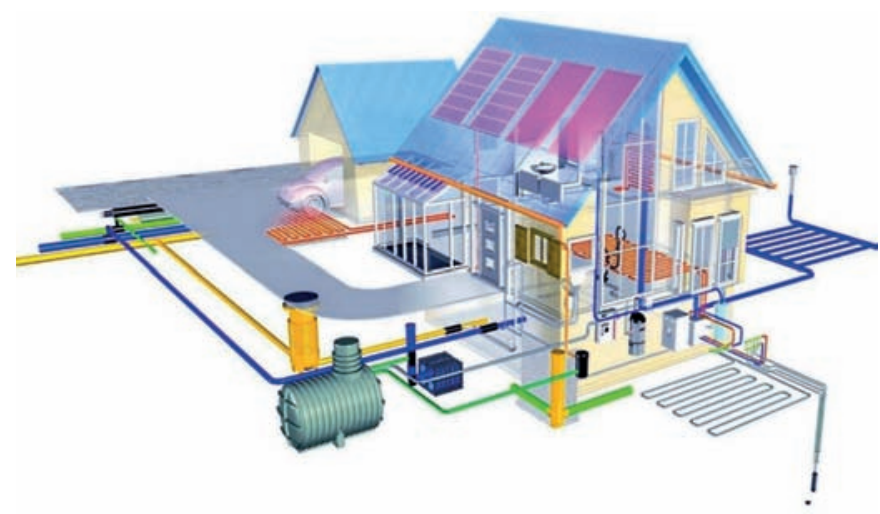

Рис. 7. Модель индивидуального жилого дома с автоматизированным узлом управления системой отопления 
Септик представляет собой очистительную систему, которая эффективно борется с фекальными массами и сточными водами. Степень очистки различных систем фильтрации может достигать 98\%. Возможности септиков также ограничены. Для сельских домов септики подходят отлично, но только в том случае, если не сливать различные воды после использования химических средств.

В системе водоотведения/канализации среди существующих схем биологической очистки бытовых и близких к ним по составу производственных сточных вод до настоящего времени не решена технико-экономическая проблема обработки и утилизации осадка и избыточного активного ила. Так, очистное сооружение глубокой биохимической очистки хозяйственно-бытовых сточных вод марки «Alta Air Master PR0 15» - идеальное решение для очистки стоков населённых пунктов, в том числе сельских, комплексов жилых зданий и других. Интенсификация процессов биологической очистки с использованием иммобилизованной микрофлоры позволяет снизить количество избыточного ила в пять-семь раз по сравнению с традиционными схемами очистки в аэротенках [13]. В целом отмечается простота и низкая стоимость монтажа названного очистного сооружения. Нет необходимости использовать крупногабаритную спецтехнику при монтаже и доставке его на объект, не требуется дополнительная теплоизоляция. Характерными являются простота и удобство в обслуживании, длительный срок эксплуатации (более 50 лет), экологическая безопасность [13].

Автоматизированный узел управления системой отопления в энергоэффективном сельском доме - это современное средство достижения температурного комфорта в зданиях а также возможность значительной экономии (рис. 7) [14].

Для создания эффективных зданий с системами жизнеобеспечения используются:

1) сети, предназначенные для обеспечения тепла в помещении. По фактору теплообеспеченности можно судить о комфортности помещения, в особенности в российских широтах. К сетям теплообеспечения относятся элементы, вырабатывающие и поставляющие тепло в здания. Это либо локальные котельные, либо автономные системы теплоснабжения дома;

2) инженерные сети, поставляющие и отводящие воду. Невозможно представить себе комфортное использование зданий, не имеющих подвода и отвода водных ресурсов. Это ключевая составляющая эксплуатации зданий. Водопоставки по назначению делятся на хозяйственно-питьевое, промышленные и противопожарные. В зависимости от назначения конструируются и водозаборные сооружения. Они бывают автономного индивидуального, локального поселкового и централизованного типа. Далее проектируются водоводы и водопроводы;

3) вентиляционные и кондиционирующие инженерные сети. Для создания здорового климата в помещении здание должно быть вентилируемым, проветриваемым. Воздух под- вергается очистке, ионизации, нагреву или охлаждению. Его осушают или увлажняют в зависимости от условий помещения.

$$
* * *
$$

1. Ближайшее будущее в сфере развития энергоснабжения сельских поселений состоит в применении энергетических систем, использующих ископаемое топливо. Наиболее актуальным является применение централизованного электроснабжения и природного газа, в первую очередь, магистрального. Для получения дополнительной тепловой и электрической энергии с целью снижения расходов ископаемого топлива могут использоваться возобновляемые источники энергии. Так, предлагается применение следующих инновационных инженерных технологий энергоснабжения на основе возобновляемых источников энергии:

а) в сельских поселениях - микро-ГЭС, малых солнечных, ветрогенераторных и гибридных электростанций;

б) в жилых, общественных и производственных зданиях солнечных батарей и коллекторов, теплового насоса, ветрогенераторных установок, рекуператоров в системе вентиляции;

2. Использование возобновляемых источников энергии в сельских поселениях предлагается путём создания локальной (на поселение) или гибридной (локальной, централизованной и автономной или централизованной и автономной) систем электроснабжения поселения; а также автономной, локальной (на два или несколько объектов) или гибридной систем теплоснабжения жилых, общественных и производственных зданий.

3. Рекомендуется строительство и реконструкция жилых домов на основе экологического стандарта дома («энергопассивный дом» и «энергоэффективный дом») для снижения энергозатрат на их эксплуатацию, создания комфортной здоровой среды жизнедеятельности. Наряду с применением современной газовой котельной в частном жилом доме, целесообразно минимизировать расходы тепла в архитектурноконструктивном решении дома («тёплый дом»); использовать автономные системы тепло- и электроснабжения на основе альтернативных источников энергии.

4. В настоящее время в связи с общим ростом объёмов потребляемой воды и нехваткой в ряде районов местных природных источников воды всё чаще возникает необходимость комплексного решения проблемы обеспечения водой всех водопользователей как сельского поселения, так и отдельного сельского населённого пункта. При этом необходима модернизация водозаборных узлов и водопроводных сетей, а также автономных систем водоснабжения жилых и общественных зданий. В крупных, больших, средних сельских населённых пунктах возможно использование централизованных систем водоснабжения. В малых населённых пунктах целесообразно использование локальных систем водоснабжения из артезианских скважин.

5. Важная инженерная проблема сельских населённых пунктов - это строительство новых и реконструкция действу- 
ющих очистных сооружений - как локальных, так и автономных. Предлагается использование инновационных очистных сооружений бытовых и промышленных сточных вод, включая канализационные насосные станции, канализационные сети. В сельских жилых и общественных зданиях, расположенных в малых населённых пунктах, рекомендуется использовать современные автономные очистные системы.

\section{Лuтература}

1. Петрова, 3.К. Планировочная организации малоэтажной экологически безопасной жилой застройки / 3.К. Петрова, В.0. Долгова - М. : Новая реальность, 2019. - 250 с.- C. 57-61, 101-105.

2. Петрова, 3.К. Пути развития сельских поселений в России: преодоление жилищной проблемы, комплексность и экологическая безопасность / 3.К. Петрова, В.0. Долгова // Фундаментальные исследования РАACH по научному обеспечению развития архитектуры, градостроительства и строительной отрасли Российской Федерации в 2017 году : Сборник научных трудов . - Москва : АСВ, 2017. - 620 с. - С. 424-433.

3. Лобанов, В.Д. Газификация сельских поселений: проблемы и пути решения [Электронный ресурс] / В.Д. Лобанов, Н.В. Аржаева. // Строительство и архитектура. 5. Теплогазоснабжение и вентиляция. - Режим доступа: http://www. rusnauka.com/pdf/282996.pdf (дата обращения 23.10.2020).

4. Статистика: Благоустройство жилищного фонда России [Электронный ресурс] // Руксперт - патриотическая энциклопедия о России и мире. - Режим доступа: https://ruxpert. ru/Статистика:Благоустройство_жилищного_фонда_России (дата обращения 23.10.2020).

5. Энергоэффективность зданий и сооружений России [Электронный ресурс] // FB. - Режим доступа: https://fb.ru/ article/369581/energoeffektivnost-zdaniy-i-soorujeniy (дата обращения 18.10.2020).

6. Как построить энергосберегающий дом: 9 главных нюансов России [Электронный ресурс] // Новосибирская компания по ремонту жилых и офисных помещений. Официальный сайт. - Режим доступа: https://www.nsk-dek.ru/sovety/33705-kakpostroit-energosberegayuschiy-dom-9-glavnyih-nyuansov.html (дата обращения 25.10.2020).

7. Энергетика. Структура по ресурсам и отраслям [Электронный ресурс] // Википедия. - Режим доступа: https:// ru.wikipedia.org/wiki/ (дата обращения 09.11.2015).

8. Альтернативные источники энергии в деревне: допустимы ли они? [Электронный ресурс] // Яндекс.Дзен. - Режим доступа: https://zen.yandex.ru/media/id/5e55ffb5aad38b32664bb5d6/ alternativnye-istochniki-energii-v-derevne-dopustimy-li-oni5e6e0421e843ec4f8c3afacd?utm_source=serp1 (дата обращения 8.10.2020).

9. Макеев, А. Какой генератор лучше поставить на дачу? [Электронный ресурс] / А. Макеев // Яндекс.Кью. - Режим достпа: https://yandex.ru/q/question/home/ kakoi_luchshe_generator_postavit_na_dachu_f2f78f9b/?utm_ source=yandex\&utm_medium $=$ wizard \&answer_id $=5 \mathrm{~b} 3 \mathrm{f} 7249$ 203b-4974-918f-ce4ac888f6ab\#5b3f7249-203b-4974-918fce4ac888f6ab (дата обращения 20.10.2020).

10. Установка тепловых насосов [Электронный реcурс] // Alter Teplo. - Режим доступа: https://alterteplo. ru/?utm_source=yandex\&utm_medium $=$ cpc\&utm campaign $=51537009 \& u t m \_$content $=8983937570 \& u t m$ term=тепловой\%20насос\%20для\%20отопления\&усl $i d=6304778299312995050$ (дата обращения 24.10.2020).

11. Водопровод из колодца в дом. Стоимость работ [Электронный ресурс] // Автономные очистные сооружения. Официальный сайт компании «Центино». - Режим доступа: https://aos-eco.ru/vodoprovod-iz-kolodca-v-dom/ (дата обращения 07.11.2020).

12. Водоснабжение из скважины в Московской области [Электронный ресурс] // Вода в доме: водоснабжение и отопление. - Режим доступа: https://doma-voda.ru/ portfolio-item/vodosnabzhenie-iz-skvazhiny/ (дата обращения 10.11.2020).

13. Локальное очистное сооружение Alta Air Master PRO 15 [Электронный ресурс] // Alta Group. Официальный сайт. Режим доступа: https://alta-group.ru/products/treatmentpla ntsofdomesticwastewater151500m3/altaairmasterpro15/ (дата обращения 05.11.2020).

14. Проектирование систем отопления и ГВС [Электронный ресурс] - Компания «Магистраль». Официальный сайт. - Режим доступа: http://magistral48.ru/engineering/ proektirovanie-sistem-otoplenija-i-gvs/ (дата обращения 05.11.2020).

\section{References}

1. Petrova Z.K., Dolgova V.0. Planirovochnaya organizatsii maloetazhnoi ekologicheski bezopasnoi zhiloi zastroiki [Planning organization oflow-rise ecologically safe residential development]. Moscow, Novaya real'nost' Publ., 2019, 250 p., pp 57-61, 101-105. (In Russ.)

2. Petrova Z.K., Dolgova V.O. Puti razvitiya sel'skikh poselenii $\checkmark$ Rossii: preodolenie zhilishchnoi problemy, kompleksnost' i ekologicheskaya bezopasnost' [Ways of development of rural settlements in Russia: overcoming the housing problem, complexity and environmental safety]. In: Fundamental'nye issledovaniya RAASN po nauchnomu obespecheniyu razvitiya arkhitektury, gradostroitel'stva i stroitel'noi otrasli Rossiiskoi Federatsii v 2017 godu [Fundamental research of the RAASN on scientific support for the development of architecture, urban planning and the construction industry of the Russian Federation in 2017], Sbornik nauchnykh trudov. Moscow, ASV Publ., 2017, 620 p., pp. 424-433. (In Russ., abstr.in Engl.)

3. Lobanov V.D., Arzhaeva N.V. Gazifikatsiya sel'skikh poselenii: problemy i puti resheniya [Gasification of rural settlements: problems and solutions]. In: Stroitel'stvo $i$ arkhitektura. 5. Teplogazosnabzhenie i ventilyatsiya [Construction and architecture. 5. Heat and gas supply and ventilation]. Access 
mode: http://www.rusnauka.com/pdf/282996.pdf (Accessed 10/23/2020). (In Russ.)

4. Statistika: Blagoustroistvo zhilishchnogo fonda Rossii [Statistics: Improvement of the housing stock of Russia]. Rukspert - patrioticheskaya entsiklopediya o Rossii i mire [Rukspert - a patriotic encyclopedia of Russia and the world]. Access mode: https://ruxpert.ru/Statistika:Blagoustroistvo_ zhilishchnogo_fonda_Rossii (Accessed 10/23/2020). (In Russ.)

5. Energoeffektivnost' zdanii i sooruzhenii Rossii [Energy efficiency of buildings and structures in Russia]. FB. Access mode: https://fb.ru/article/369581/energoeffektivnostzdaniy-i-soorujeniy ( Accessed 10/18/2020). (In Russ.)

6. Kak postroit' energosberegayushchii dom: 9 glavnykh nyuansov Rossii [How to build an energy-saving house: 9 main nuances of Russia]. Novosibirskaya kompaniya po remontu zhilykh i ofisnykh pomeshchenii. Ofitsial'nyi sait [Novosibirsk company for the repair of residential and office premises. Official site]. Access mode: https://www.nsk-dek.ru/sovety/33705-kakpostroit-energosberegayuschiy-dom-9-glavnyih-nyuansov.html (Accessed 10/25/2020). (In Russ.)

7. Energetika. Struktura po resursam i otraslyam [Energy. Structure by resources and industries]. Vikipediya [Wikipedia]. Access mode: https://ru.wikipedia.org/wiki/ (Accessed 11/09/2015). (In Russ.)

8. Al'ternativnye istochniki energii v derevne: dopustimy li oni? [Alternative energy sources in the village: are they acceptable?]. Yandeks.Dzen. Access mode: https:// zen.yandex.ru/media/id/5e55ffb5aad38b32664bb5d6/ alternativnye-istochniki-energii-v-derevne-dopustimy-lioni-5e6e0421e843ec4f8c3afacd?utm_source=serp1 (Accessed 10/08/2020 ). (In Russ.)

9. Makeev A. Kakoi generatorluchshe postavit' na dachu? [Which generator is better to put in the country?]. Yandeks. K'yu
[Yandex.Q]. Access mode: https://yandex.ru/q/question/home/ kakoi_luchshe_generator_postavit_na_dachu_f2f78f9b/?utm_ source=yandex\&utm_medium =wizard\&answer_id=5b3f7249203b-4974-918f-ce4ac888f6ab\#5b3f7249-203b-4974-918fce4ac888f6ab (Accessed 10/20/2020). (In Russ.)

10. Ustanovka teplovykh nasosov [Installation of heat pumps]. Alter Teplo. Access mode: https://alterteplo. ru/?utm_source=yandex\&utm_medium $=$ cpc\&utm_ campaign $=51537009 \& u t m \_$content $=8983937570 \& u t m$ term=teplovoi $\% 20$ nasos $\% 20$ dlya $\% 20$ otopleniya \&ycl $i d=6304778299312995050$ (Accessed 10/24/2020). (In Russ.)

11. Vodoprovod iz kolodtsa $v$ dom. Stoimost' rabot [Plumbing from the well to the house. The cost of work]. Avtonomnye ochistnye sooruzheniya. Ofitsial'nyi sait kompanii «Tsentino» [Autonomous treatment facilities. Official site of the company "Centino"]. Access mode : https://aos-eco.ru/vodoprovod-izkolodca-v-dom/ (Accessed 11/07/2020). (In Russ.)

12. Vodosnabzhenie iz skvazhiny $\vee$ Moskovskoi oblasti [Water supply from a well in the Moscow region]. Voda $v$ dome: vodosnabzhenie $i$ otoplenie [Water in the house: water supply and heating. Website]. Access mode: https://doma-voda.ru/ portfolio-item/vodosnabzhenie-iz-skvazhiny/ (Accessed 11/10/2020). (In Russ.)

13. Lokal'noe ochistnoe sooruzhenie Alta Air Master PRO 15 [Local treatment plant Alta Air Master PRO 15]. Alta Group. Ofitsial'nyisait [AltaGroup. Officialsite]. Access mode: https://altagroup.ru/products/treatmentplantsofdomesticwastewater1515 00m3/altaairmasterpro15/ (Accessed 11/05/2020). (In Russ.)

14. Proektirovanie sistem otopleniya i GVS [Design of heating and hot water supply systems]. Kompaniya «Magistral'». Ofitsial'nyi sait ["Magistral" Company. Official site]. Access mode: http://magistral48.ru/engineering/proektirovaniesistem-otoplenija-i-gvs/ ( Accessed 11/05/2020). (In Russ.) 